\title{
LOGARITHMIC MEANS AND SUMMABILITY BY THE CIRCLE METHODS
}

\section{R. PARAMESWARAN}

ABSTRACT. It is proved that if the logarithmic means of a sequence $\left\{s_{n}\right\}$ satisfy a certain order condition then the sequence $\left\{s_{n}\right\}$ will be summable by every circle method (Kreisverfahren) stronger than convergence; the condition is shown to be a best possible one, for even summability by the collective circle method. A second set of conditions leading to the conclusion of summability by every circle method is also proved.

1. Introduction. Given a sequence $\left\{s_{n}\right\}$, its logarithmic means $t_{n}(n=$ $0,1, \ldots, \ldots)$ are defined by

$$
t_{0}=s_{0}, \quad t_{1}=s_{1} \quad \text { and } \quad t_{n}=\tau_{n} / \log n \quad(n \geq 2)
$$

where

$$
\tau_{n}=\sum_{k=0}^{n} \frac{s_{k}}{k+1} \quad(n \geq 0) .
$$

If $\lim _{n \rightarrow \infty} t_{n}=\mu$ exists we say that $\left\{s_{n}\right\}$ is summable by the logarithmic method $l$. Let $\Gamma$ denote the family of summability methods consisting of all those Euler methods $E_{a}$, Taylor methods $T_{a}$, Meyer-König methods $S_{a}$, Valiron methods $F_{\alpha}$ and the Borel exponential method $B$-the "circle family" (Kreisverfahren)-which are permanent (= regular) and strictly stronger than convergence. For the definitions and basic properties of the various summability methods, see Hardy [1], Meyer-König [3] and Zeller and Beekmann [5].

For any sequence $\left\{x_{n}\right\}$, the symbols $x_{n}=O_{L}\left(n^{a}\right), x_{n}=O\left(n^{a}\right)$ and $x_{n}=$ $o\left(n^{\alpha}\right)$ will denote, as usual, that $\lim \inf n^{-\alpha} x_{n}>-\infty, \lim \sup \left|n^{-\alpha} x_{n}\right|<\infty$ and $\lim n^{-\alpha} x_{n}=0$, respectively; the $C_{1}$-transform of $\left\{x_{n}\right\}$ will be denoted by $\left\{x_{n}^{1}\right\}$, so that $x_{n}^{1}=\left(x_{0}+\cdots+x_{n}\right) /(n+1)$ for $n \geq 0$. Finally, throughout this note, the sequences labelled $\left\{s_{n}\right\},\left\{t_{n}\right\}$ and $\left\{r_{n}\right\}$ are assumed to be related by equations (1) and (2).

\section{Theorems.}

Theorem 1. (a) Let $\left\{s_{n}\right\}$ be a sequence such that there exists a number $\mu$ with

$$
t_{n} \log n=\mu+o\left(n^{-1 / 2}\right) \text {. }
$$

Then $\left\{s_{n}\right\}$ is summable by every member of the family $\Gamma$.

In particular, the condition $n^{1 / 2} t_{n} \log n=o(1)$ implies that $\left\{s_{n}\right\}$ is sum-

Received by the editors July 19, 1974.

AMS (MOS) subject classifications (1970). Primary 40E05, 4CG99; Secondary 40D05.

Key words and phrases. Logarithmic means, summability, circle methods. 
mable by every member of the family $\Gamma$.

(b) In the above, the symbol o( $\left.n^{-1 / 2}\right)$ cannot be replaced by $O\left(n^{-1 / 2}\right)$. Indeed, there exists a $C_{1}$-summable bounded sequence $\left\{s_{n}\right\}$ such that it is not summable by any member of $\Gamma$ and

$$
t_{n} \log n=O\left(n^{-1 / 2}\right) \text {. }
$$

The last assertion shows that Theorem $1(\mathrm{a})$ is the best possible in a strong sense.

To prove Theorem 1(a) we use the following

Lemma (Parameswaran [4, Theorem 4]). If $\left\{s_{n}\right\}$ is a sequence and $\mu a$ number with

$$
\left(s_{0}+s_{1}+\cdots+s_{n}\right) /(n+1)=\mu+o\left(n^{-1 / 2}\right),
$$

then $\left\{s_{n}\right\}$ is summable $($ to $\mu)$ by every member of $\Gamma$.

\{Note. In [4], the Borel method $B$ also should have been mentioned as a member of $\Gamma$; there are also some minor misprints in the proof of Theorem 1.\}

Proof of Theorem 1(a). From relation (2) we see that

$$
s_{n}=(n+1)\left(\tau_{n}-\tau_{n-1}\right) \text { for } n \geq 0
$$

and hence

$$
s_{0}+s_{1}+\cdots+s_{n}=(n+1) \tau_{n}-\left(0+\tau_{0}+\cdots+\tau_{n-1}\right)
$$

or

$$
s_{n}^{1}=\tau_{n}-\theta_{n}^{1} \quad(n \geq 0)
$$

where $\theta_{n}=\tau_{n-1}(n \geq 0)$, with $\tau_{-1}=0$. Writing $u_{n}=\tau_{n}-\mu, u_{-1}=-\mu$, we see that

$$
\begin{aligned}
s_{n}^{1} & =\left(u_{n}+\mu\right)-(n+1)^{-1} \sum_{m=0}^{n}\left(u_{m-1}+\mu\right) \\
& =u_{n}-(n+1)^{-1} \sum_{0}^{n} u_{m-1} \\
& =o\left(n^{-1 / 2}\right)+o\left(n^{-1 / 2}\right) \quad[\text { by }(3)] \\
& =o\left(n^{-1 / 2}\right) .
\end{aligned}
$$

Hence the sequence $\left\{s_{n}\right\}$ is summable by every member of $\Gamma$, by the Lemma.

Proof of Theorem $\mathbf{1}(\mathbf{b})$. Given an arbitrary sequence $\left\{x_{n}\right\}$, its counting function $\omega(n)$ is defined as follows: $\omega(n)$ is the number of nonzero terms $x_{n_{\nu}}$ with $n_{\nu} \leq n$. G. Lorentz [2] has shown that if $\Omega(n)$ is an arbitrary positive monotone increasing function and $E_{a}$ a regular Euler method stronger than convergence (i.e. $0<\alpha<1$ and $E_{\alpha}$ is defined as in [2] or [5]), then $E_{\alpha}$ will sum every bounded sequence $\left\{x_{n}\right\}$ for which $\omega(n) \leq \Omega(n)$ if and only if $\Omega(n)=o\left(n^{1 / 2}\right)$. Hence there exists a bounded sequence $\left\{x_{n}\right\}$ with $\omega(n)=$ 
$O\left(n^{1 / 2}\right)$ and $\left\{x_{n}\right\}$ not $E_{a}$ summable. Let $\left\{x_{n}\right\}$ be such a sequence. We have then $x_{0}+x_{1}+\cdots+x_{n}=O\left(n^{1 / 2}\right) \quad$ or $\quad x_{n}^{1}=\left(x_{0}+x_{1}+\cdots+x_{n}\right) /(n+1)=O\left(n^{-1 / 2}\right)$.

We define the sequences $\left\{\tau_{n}\right\}$ and $\left\{s_{n}\right\}$ by setting $\tau_{n}=x_{n}^{1}$ for all $n \geq 0$. Then it follows from (5) that

$$
s_{n}=x_{n}-\theta_{n} \quad(n \geq 0)
$$

We note that $\left\{\theta_{n}\right\}$, being a translate of $\left\{\tau_{n}\right\}=\left\{x_{n}^{1}\right\}$ is convergent; and $\left\{x_{n}\right\}$ is bounded and not $E_{\alpha}$-summable. Hence we see from (6) that $\left\{s_{n}\right\}$ is bounded and not $E_{a}$-summable. Since the members of $\Gamma$ are all equivalent for bounded sequences (Meyer-König [3, Satz 25]), this means that $\left\{s_{n}\right\}$ is not summable by any member of $\Gamma$. This proves the theorem.

Theorem 2. Let $\left\{s_{n}\right\}$ be a sequence and $\mu$ a real number such that

$$
s_{n}=O_{L}(1)
$$

and

$$
\frac{1}{n} \sum_{k=1}^{n} k^{1 / 2} t_{k} \log k=\mu+o\left(n^{-1 / 2}\right)
$$

where $\left\{t_{k}\right\}$ is defined by (1) and (2). Then $\left\{s_{n}\right\}$ is summable by every member of $\Gamma$.

Proof. Set $\phi_{k}=\tau_{k}-\mu k^{-1 / 2}(k \geq 1)$. Then (8) gives us

$$
\frac{1}{n} \sum_{1}^{n} k^{1 / 2} \phi_{k}=\frac{1}{n} \sum_{1}^{n}\left(k^{1 / 2} \tau_{k}-\mu\right)=o\left(n^{-1 / 2}\right)
$$

and hence $\phi_{n}=o(1)$; also, the Lemma shows that

$$
\text { the sequence }\left\{k^{1 / 2} \phi_{k}\right\} \text { is } E_{1 / 2} \text {-summable to } 0 \text {. }
$$

From relation (4) we have for $n \geq 1$ :

$$
\begin{aligned}
s_{n} & =(n+1)\left(\tau_{n}-\tau_{n-1}\right) \\
& =\left(\frac{n+1}{n}\right)\left\{n^{1 / 2}\left[n^{1 / 2} \tau_{n}-(n-1)^{1 / 2} \tau_{n-1}\right]\right\}-\left(\frac{n+1}{n}\right) n^{1 / 2}\left[n^{1 / 2}-(n-1)^{1 / 2}\right] \tau_{n-1} \\
& =\left(\frac{n+1}{n}\right) n^{1 / 2}\left\{n^{1 / 2} \phi_{n}+\mu-(n-1)^{1 / 2} \phi_{n-1}-\mu\right\}-\left(\frac{n+1}{n}\right) n^{1 / 2} O\left(n^{-1 / 2}\right)\left(\phi_{n-1}+\mu n^{-1 / 2}\right) \\
& =\left(\frac{n+1}{n}\right) n^{1 / 2} \Delta\left(n^{1 / 2} \phi_{n}\right)-\left(\frac{n+1}{n}\right) O\left(\phi_{n-1}\right)+O\left(n^{-1 / 2}\right)
\end{aligned}
$$

[where for any sequence $\left\{u_{n}\right\}$ we define $\Delta u_{n}=u_{n}-u_{n-1}$ ]

$=\left(\frac{n+1}{n}\right) n^{1 / 2} \Delta\left(n^{1 / 2} \phi_{n}\right)+o(1) \quad[$ by (9) ]

$=O_{L}(1) \quad[$ by $(7)]$. 
Hence

$$
n^{1 / 2} \Delta\left(n^{1 / 2} \phi_{n}\right)=O_{L}(1)
$$

Hence (10) yields, in view of the well-known Tauberian theorem for Euler methods, that the sequence $\left\{n^{1 / 2} \phi_{n}\right\}$ converges to 0 . Thus the sequence $\left\{n^{1 / 2} \tau_{n}-\mu\right\}$ converges to 0 ; i.e.

$$
\tau_{n}=\mu n^{-1 / 2}+o\left(n^{-1 / 2}\right) .
$$

Now

$$
\begin{aligned}
s^{1} & =\tau_{n}-(n+1)^{-1} \sum_{0}^{n} \tau_{k}+\tau_{n} /(n+1) \quad[\text { by }(5)] \\
& =\mu n^{-1 / 2}+o\left(n^{-1 / 2}\right)-(n+1)^{-1} \sum_{1}^{n}\left[\mu k^{-1 / 2}+o\left(k^{-1 / 2}\right)\right] \quad[\text { by }(12)] \\
& =\mu n^{-1 / 2}+o\left(n^{-1 / 2}\right)-\mu(n+1)^{-1}\left[2 n^{1 / 2}+O(1 / n)+o\left(n^{1 / 2}\right)\right] \\
& =-\mu(n+1)^{-1 / 2}+o\left(n^{-1 / 2}\right) .
\end{aligned}
$$

If we define $\left\{u_{n}\right\}$ by setting $u_{n}^{1}=\mu(n+1)^{-1 / 2}$ then it is easy to verify that

$$
\left\{u_{n}\right\} \text { is a convergent sequence. }
$$

But (13) gives $s_{n}^{1}+u_{n}^{1}=o\left(n^{-1 / 2}\right)$ and hence, by the Lemma, the sequence $\left\{s_{n}+u_{n}\right\}$ is summable by every member of $\Gamma$. In view of (14), this proves the theorem.

\section{REFERENCES}

1. G. H. Hardy, Divergent series, Clarendon Press, Oxford, 1949. MR 11, 25.

2. G. Lorentz, Direct theorems on methods of summability, Canad. J. Math. 1 (1949), 305-319. MR 11, 242.

3. W. Meyer-König, Untersuchungen über einige verwandte Limitierungsverfahren, Math. Z. 52 (1949), 257-304. MR 11, 242.

4. M. R. Parameswaran, On summability functions for the circle family of methods, Proc. Nat. Inst. Sci. India Part A 25 (1959), 171-175. MR 21 \#6489.

5. K. Zeller and W. Beekmann, Theorie der Limitierungsverfahren, Zweite, erweiterte und verbesserte Auflage, Ergebnisse der Mathematik und ihrer Grenzgebiete, Band 15, Springer-Verlag, Berlin and New York, 1970. MR $41 \# 8863$.

DEPARTMENT OF MATHEMATICS, UNIVERSITY OF MANITOBA, WINNIPEG R3T 2N2, CANADA 